Sibbritt D, Catling C, Adams J, Shaw A, Homer CSE. (2014) The self-prescribed use of aromatherapy oils by pregnant women. Women and Birth, 27: 41-45.

\title{
Title: The self-prescribed use of aromatherapy oils by pregnant women.
}

\section{Introduction}

Complementary and alternative medicine (CAM) refers to those practices, therapies and products not traditionally associated with the conventional medical community or the medical curriculum, such as acupuncture, naturopathy, and aromatherapy among others. ${ }^{1}$ CAM use is becoming increasing popular, especially amongst women. ${ }^{1,2,3}$ The rates of CAM use internationally vary considerably from $26 \%$ in England ${ }^{4}$ to $76 \%$ in Japan ${ }^{5}$. Within Australia the prevalence of CAM use has been reported to be $69 \% .{ }^{6}$ One area of practice where CAM is making its presence felt is in pregnancy and birth. ${ }^{7}$

\section{CAM use in pregnancy}

The prevalence of CAM use in pregnancy has been commonly reported to range between 20\%-60\%. ${ }^{8}$ The most popular CAM used by pregnant women include herbal medicine, vitamin and mineral supplements, relaxation therapies and aromatherapy. ${ }^{9,} 10,11$ The popularity of CAM for pregnancy and birth may be representative of the fact that both health professionals and women are striving to regain control of their needs and health issues in the ever-increasingly medicalised sphere of maternity care. ${ }^{8,12}$ Interestingly, it has been highlighted that pregnant women who use CAM are more likely to be using more than one therapy/modality interchangeably ${ }^{13}$ and that such women will predominantly seek information regarding CAM from friends, family members and the internet, rather than from health professionals. ${ }^{8,10}$ This demonstrates that a high proportion of women are often selfprescribing rather than seeking professional guidance regarding CAM use in pregnancy. 


\section{Issues related to self-prescribed CAM use}

Although the body of research focused on CAM is gradually evolving, the literature specifically related to the safety and trends of use within pregnancy is still lacking. Therefore, this raises concerns about the risks related to women's self-prescribed use of CAM therapies within pregnancy in the absence of rigorous research. ${ }^{14}$ Here we define self-prescribed use of CAM as the use of complementary and alternative medicines or products purchased over-thecounter from a health food store, pharmacy or supermarket without advice from a health care practitioner. Furlow et al, (2008) stated that $63 \%$ of pregnant women did not consult with their health professional before commencing use of CAM. The majority of women stated that they did not disclose their CAM use simply because they were never asked about it by their health professional. ${ }^{10}$ Alternatively, women may choose not to disclose their CAM use for fear of a negative response from their health professional. ${ }^{15}$ There are concerns regarding possible adverse reactions between medications/conventional treatments and CAM and so this emphasises the need for greater collaboration between women and their care providers to ensure women are using CAM safely during their pregnancy. ${ }^{2,7}$

\section{Aromatherapy use within pregnancy}

Aromatherapy is the therapeutic use of highly concentrated essential oils and is a popular form of self-prescribed CAM used by pregnant women. ${ }^{9,11}$ Evidence for the efficacy of aromatherapy during pregnancy, birth and postpartum is lacking with only two RCT studies included within a recent Cochrane Database Systematic Review. ${ }^{16}$ Both studies were underpowered resulting in a lack of statistical significance and external validity due to small sample sizes. However, it is important to note that there are a number of challenges to conducting RCTs of aromatherapy, such as: recruitment and randomisation can be 
problematic because of participants' beliefs and preferences; the identification of an appropriate placebo is often difficult or impossible, thus making the blinding of patients and researchers difficult; and there is little incentive for aromatherapists to do research, coupled with inadequate research infrastructure, and poor access to research funding. ${ }^{17,18}$

Moving beyond such RCT research, studies have reported aromatherapy use in labour as being beneficial. Burns et al (2000) found that the use of aromatherapy was rated as useful in labour by over $50 \%$ of the 8,058 mothers who participated. ${ }^{19}$ The study also found a significant 5.8\% reduction in the use of pethidine for labour pain following the introduction of aromatherapy. ${ }^{19}$ The findings of this study led to a large UK teaching hospital incorporating protocols for the use of aromatherapy within their maternity unit ${ }^{20}$ and, further afield, aromatherapy is reportedly available within $76.6 \%$ of obstetric departments in Germany. $^{21}$

It has been suggested that women's use of CAM, such as aromatherapy, may be motivated by a desire to avoid ingesting pharmaceutical medications during pregnancy, a position supported by women's common perception that CAM is 'natural' and 'free of side effects' (while not being fully aware of any associated risks). ${ }^{9}$ Indeed, the use of volatile aromatherapy essential oils can be potentially unsafe in pregnancy and commentators have advised women to seek guidance from trained professionals (such as aromatherapists) rather than attempt self-administration. ${ }^{22}$ While it is important to acknowledge that toxicity is related to dose and therefore mode of delivery, jasmine, juniper, peppermint, clove, cedarwood, sage and rosemary are all examples of aromatherapy essential oils that should be avoided during pregnancy, with some of them possessing abortifacient properties. ${ }^{21}$ There are also essential oils such as clary sage, fennel and frankincense that should be restricted to use 
in the third trimester due to their emmenagogic properties ${ }^{23}$ and certain oils such as clary sage should only be used under professional guidance. ${ }^{23}$

The potential dangers of aromatherapy use by pregnant women highlights the significance of better understanding where and how pregnant women are obtaining information regarding their CAM use. Without access to quality information, pregnant women’s decision-making around the use of essential oils may be compromised, with serious implications for their pregnancy. Health professionals’ lack of knowledge about CAM safety ${ }^{2}$ and lack of awareness about where to refer women for guidance regarding these medicines has been considered by some to result in an increasing number of women self-administering CAM. ${ }^{24}$

Examples of common pregnancy symptoms for which women use aromatherapy include nausea, headache, asthma, urinary tract infection, allergies/hayfever, anxiety and depression, haemorrhoids, insomnia, labour pain relief, oedema and for relaxation purposes. ${ }^{8,25}$ For symptoms/ailments such as asthma, allergies and hayfever, pregnant women may choose CAM, such as aromatherapy, as an alternative to medicated forms of relief. Although many anti-histamine medications are viewed as relatively safe for use during pregnancy, many women may still be hesitant, especially given that such symptoms may be endured throughout pregnancy and long-term use of anti-histamine use is not ideal. ${ }^{26}$ In relation to headache treatment in pregnancy, the safety of simple analgesics such as paracetamol, codeine and non-steroidal anti-inflammatory drugs (NSAID's) such as ibuprofen is now debatable. ${ }^{27}$ There have been links between paracetamol use during pregnancy and an increased likelihood of childhood asthma ${ }^{27}$, between use of NSAID’s and higher miscarriage rates and possible links between codeine use in pregnancy and increased risk of cleft palates 
in infants. ${ }^{28}$ In view of such evidence, it is understandable that women may seek CAM, including aromatherapy, in an attempt to reduce any potential effects on fetal development.

The use of aromatherapy by pregnant women has been largely under-researched and there has been no detailed empirical study of the prevalence and characteristics of such users undertaken in Australia to date. In response, this paper - reporting the first examination of the prevalence and characteristics of aromatherapy users amongst a large, nationally representative sample of pregnant Australian women - is a first step towards addressing this significant research gap and provides findings of importance to consumers, practitioners and health policy-makers.

\section{Methods}

\section{Sample}

This research was conducted as part of the Australian Longitudinal Survey on Women's Health (ALSWH) which was designed to investigate multiple factors affecting the health and well being of women over a 20-year period. Women in three age groups (“young” 18-23, "mid age” 45-50 and "older” 70-75 years) were randomly selected from the national Health Insurance Commission database. A total of 106,000 women in the three age groups were sent an invitation to participate and a questionnaire. Reminder letters, a nation-wide publicity campaign, information brochures, a freecall number for inquiries, and the option of completing the questionnaire by telephone in English or in the respondent's own language, were used to encourage participation. Response rates were $41 \%(n=14,792), 54 \%(n=$ $14,200)$ and $36 \%(n=12,614)$ for the three age groups, respectively. The focus of the study reported here are women from the young cohort who have been surveyed five times over a 
thirteen year period (1996-2009). ${ }^{29}$ The respondents to the baseline survey have been shown to be broadly representative of the national population of women in the target age group. ${ }^{30}$ Wherever possible, previously validated questions or scales were included. Where appropriate instruments were not available or not suitable, the existing measures were modified or questions and scales were constructed and tested by the study investigators. ${ }^{29}$ The analyses reported here are restricted to the most recent survey (survey 5) of this young cohort, which was conducted in 2009 (when the women were aged 31-36 years). The ALSWH has ongoing ethical clearance from both the University of Newcastle and University of Queensland’s Human Research Ethics Committees.

\section{Measures of demographic characteristics}

Postcode of residence was used to classify area of residence as urban or non-urban. Women were asked about their current marital status and the highest educational qualification completed.

\section{Measure of health status}

Women were asked to indicate if they were currently pregnant. In terms of illness, women were asked how often they experienced a list of common symptoms in the previous twelve months. This list included: allergies/hay fever, headaches/ migraines, back pain, stiff/painful joints, vaginal discharge or irritation, severe tiredness, urine that burns or stings, leaking urine, haemorrhoids, and sleeping problems. Women were also asked whether a doctor had ever told them that they had any medical conditions from a list provided which included: asthma, low iron (iron deficiency or anaemia), hypertension, depression, anxiety disorder, and urinary tract infection (UTI). 


\section{Health service utilisation}

The women were asked about their frequency of consultations in the previous twelve months with a general practitioner (GP) and a specialist doctor. In addition, they were asked if they had consulted with a midwife, massage therapist, acupuncturist, naturopath/herbalist, chiropractor/osteopath, other alternative health practitioner (eg. aromatherapist, homeopath, reflexologist, iridologist) in the previous twelve months.

\section{Use of aromatherapy oils}

Women were asked how often (ie. never, rarely, sometimes, often) they had self-prescribed the use of aromatherapy oils, for their own health, in the previous twelve months. Women who indicated that they used aromatherapy oils either "sometimes" or "often” were considered to be users of aromatherapy oils.

\section{Statistical analyses}

Chi-square tests were used to examine bivariate associations. Multiple logistic regression modelling was employed to determine the statistically significant factors associated with aromatherapy oils use. All the demographic, symptoms and diagnoses variables listed above were entered into a model and then a stepwise backward elimination process was employed, using a likelihood ratio test, to eventually produce the most parsimonious model.

\section{Results}

In 2009 (survey 5) there were 8,200 women of which 804 (9.8\%) were pregnant at the time of the survey. Of the pregnant women, $62.2 \%$ resided in an urban area, $98.4 \%$ were in a married or defacto relationship, and $62.4 \%$ had a university education. 
Self-prescribed aromatherapy oils were used by $15.2 \%$ of pregnant women and $17.5 \%$ of non-pregnant women, which was not significantly different $(\mathrm{p}=0.101)$. Table 1 shows the associations between consultations with health care practitioners and self-prescribed use of aromatherapy oils, by pregnant and non-pregnant women. In comparison to pregnant women who did not use aromatherapy oils, pregnant women who used aromatherapy oils were less likely to consult with a specialist three or more times $(\mathrm{p}=0.004)$, but more likely to consult with a massage therapist $(\mathrm{p}=0.001)$, naturopath/herbalist $(\mathrm{p}<0.001)$, or other alternative practitioner ( $\mathrm{p}=0.035)$. For non-pregnant women, those who self-prescribed use of aromatherapy oils were more likely to consult with all CAM practitioners (all $\mathrm{p}<0.001$ ) and GPs ( $\mathrm{p}=0.001$ ), compared with non-pregnant women who did not use aromatherapy oils.

In comparison to pregnant women who did not use aromatherapy oils, those who selfprescribed use of aromatherapy oils were more likely to have experienced allergies/hayfever $(\mathrm{p}=0.039)$, headaches/migraines $(\mathrm{p}=0.031)$, and UTIs $(\mathrm{p}=0.003)$. A similar association was also found between self-prescribed aromatherapy oil use and these three symptoms for nonpregnant women. Further, for non-pregnant women, self-prescribed use of aromatherapy oils was significantly higher for women who had experienced back pain, stiff/painful joints, sleep problems, vaginal discharge, severe tiredness, low iron levels, depression, and anxiety.

The logistic regression modelling resulted in only two symptoms (out of all the symptoms and diagnoses) being deemed statistically significant predictors of self-prescribed use of aromatherapy oils by pregnant women, these being allergies/hayfever and UTI (data not shown). Specifically, the odds of a pregnant women self-prescribing use of aromatherapy oils is: 1.57 (95\% CI: $1.01,2.43)$ times greater if they have allergies/hayfever, compared to 
women without allergies/hayfever; and 2.26 (95\% CI: 1.34, 3.79) times greater if they have a UTI, compared to women without a UTI.

\section{Discussion}

This study represents the first examination of pregnant women's self-prescribed use of aromatherapy oils based on analyses of a large, nationally representative sample of Australian women. The study presents three key findings. The study reveals that aromatherapy oils were used by a considerable proportion of pregnant women, a finding supported by previous work by Skouteris et al (2008) who reported a similar prevalence of aromatherapy oils use by pregnant women in Australia. This is a significant finding, especially given that the prevalence of aromatherapy oils use by pregnant women is similar to that of non-pregnant women, and appears to suggest that pregnant women are not reducing or forgoing their use of aromatherapy oils and as such may be unaware of the potential risks of aromatherapy oil use during pregnancy. This is of greater concern when aromatherapy oil use is self-prescribed.

Our analyses also identified associations between pregnant women's use of aromatherapy oils and their consultations with various providers. Pregnant women who consult with a massage therapist or naturopath/herbalist are more likely to use aromatherapy oils. This is perhaps unsurprising given that massage therapists and naturopaths often use essential oils in their own practice. $^{31,32}$ Nevertheless, further research is needed to determine the level of education such CAM therapists receive in training regarding the safe use of aromatherapy oils by pregnant women. Conversely, pregnant women are less likely to use aromatherapy oils if they have consulted a specialist. Given that obstetricians consider aromatherapy oils use to be of no benefit for pregnant women, ${ }^{9}$ this finding may reflect obstetricians' discouragement of 
aromatherapy oils use, or alternatively, obstetricians may be cautious in recommending the use of CAM to their patients due to the current limited educational opportunities for undergraduate and postgraduate training in the area of CAM. ${ }^{9}$ There was no significant relationship between self-prescribed use of aromatherapy oils by pregnant women and consultation with a midwife. This is an interesting finding in light of the review by Hall et al. (2012) which reported that most midwives perceived their education in CAM to be inadequate.

Finally, it appears from our analyses that aromatherapy oils are used by a substantial number of pregnant women to treat allergies/hayfever and/or UTI. In these cases, it is possible that the aromatherapy oils use may be an attempt by these women to avoid using pharmaceutical options such as antihistamines or antibiotics, due to concerns over potential harm to their unborn child. ${ }^{9}$ Further, UTI is a known risk factor for preterm birth and small-forgestational-age babies ${ }^{33}$ and this raises concern if aromatherapy oils are used but are ineffective in treating UTI. Further research is required to determine the specific aromatherapy oils used by pregnant women and to examine the concerns of pregnant women regarding the potential harm of conventional treatments for allergies and UTI.

The interpretation of our findings is potentially limited by the fact that the data analysed is self-reported by the participants and so our results may be open to the effects of recall bias. In addition, the medical conditions and symptoms were defined by self-report and the lack of confirmatory diagnosis could potentially bias findings. The main strengths of this study are the large sample size and that the sample is nationally representative. 


\section{Conclusion}

Our study highlights a considerable use of aromatherapy oils by pregnant women. Regardless of the reasons why pregnant women choose to use aromatherapy oils, there is a clear need for greater communication between practitioners and pregnant women regarding the use of aromatherapy oils as well a need to educate health care practitioners that pregnant women in their care may be using aromatherapy oils, some of which may be unsafe. 


\section{References}

1) Adams J, Sibbritt D, Easthope G, Young A. The profile of women who consult alternative health practitioners in Australia. Medical Journal of Australia 2003; 179: 297-300.

2) Adams J. Growing popularity of complementary and alternative medicine during pregnancy and implications for healthcare providers. Expert Review in Obstetrics and Gynecology 2011; 6(4): 365-6.

3) Steinsbekk A, Adams J, Sibbritt D, Johnsen R, Jacobsen G, Holmen J. Sociodemographic characteristics and health perceptions among male and female CAM users in a Norwegian total population study (HUNT 2). Forschende Komplementärmedizin 2008; 15: 146-151.

4) Hunt KJ, Coelho HF, Wider B, Perry R, Hung SK, Terry R, Ernst E. Complementary and alternative medicine use in England: Results from a national survey. International Journal of Clinical Practice 2010; 64: 1496-1502.

5) Ock SM, Choi JY, Cha YS, Lee J, Chun MS, Huh CH, Lee SY, Lee SJ. The use of complementary and alternative medicine in a general population in South Korea: results from a national survey in 2006. Journal of Korean Medical Science 2009; 24(1):1-6.

6) Xue CC, Zhang AL, Lin V, Da Costa C, Story DF. Complementary and alternative medicine use in Australia: a national population based survey. Journal of Alternative \& Complementary Medicine 2007; 13: 643-650. 
7) Adams J, Lui CW, Sibbritt D, Broom A, Wardle J, Homer C. Attitudes and referral practices of maternity care professionals with regard to complementary and alternative medicine: an integrative review. Journal of Advanced Nursing 2011; 67(3): 472-483.

8) Adams J, Lui C, Sibbritt D, Broom A, Wardle J, Homer C, Beck S. Women’s use of complementary and alternative medicine during pregnancy: A critical review of the literature. Birth 2009; 36(3): 237-245.

9) Gaffney L, Smith CA. Use of complementary therapies in pregnancy: The perceptions of Obstetricians and Midwives in South Australia. Australian and New Zealand Journal of Obstetrics and Gynaecology 2004; 44(1): 24-29.

10) Furlow ML, Patel DA, Sen A, Liu R. Physician and patient attitudes towards complementary and alternative medicine in obstetrics and gynecology. BMC Complementary and Alternative Medicine 2008; 8(35): 1-8.

11) Skouteris H, Wertheem EH, Rallis S, Paxton SJ, Kelly L, Milgrom J. Use of complementary and alternative medicines by a sample of Australian women during pregnancy. Australian and New Zealand Journal of Obstetrics and Gynaecology 2008; 48: 384-390.

12) Hall HG, Mckenna LG, Griffiths DL. Midwives support for Complementary and Alternative Medicine: A literature review. Women and Birth 2012; 25(1): 4-12. 
13) Steel A, Adams J, Sibbritt, D, Broom A, Gallois C, Frawley J. Utilisation of complementary and alternative medicine (CAM) practitioners within maternity care provisions: results from a nationally representative cohort study of 1,835 pregnant women. BMC Pregnancy and Childbirth 2012; 12: 146.

14) Tiran D. Complementary therapies in clinical practice: midwives' and obstetricians' appreciation of risk. Complementary Therapies in Clinical Practice 2006; 12: 126-31.

15) Holst L, Wright H, Nordeng S, Haavik N. Use of herbal preparations during pregnancy: focus group discussion among expectant mothers attending a hospital antenatal clinic in Norwich, UK. Complementary Therapies in Clinical Practice 2009; 15: 225-229.

16) Smith C, Collins C, Crowther C. Cochrane Database Systematic Review. Aromatherapy for Pain Management in Labour (Review), Wiley, 2011.

17) Verhoef MJ, Casebeer AL, Hilsden RJ. Assessing efficacy of complementary medicine: adding qualitative research methods to the "Gold Standard". Journal of Alternative and Complementary Medicine 2002; 8(3): 275-281.

18) Pirotta M. Towards the application of RCTs for CAM: methodological challenges. In: Adams J (Ed.), Researching Complementary and Alternative Medicine. London: Routledge; 2007. p. 52-71. 
19) Burns E, Blamey C, Ersser S, Barnetson L, Lloyd A. An Investigation into the use of aromatherapy in intrapartum midwifery practice. Journal of Alternative and Complementary Medicine 2000; 2: 141-147.

20) Mousley S. Audit of an aromatherapy service in a maternity unit. Complementary Therapies in Clinical Practice 2005; 11: 205-210.

21) Munsteadt K, Schroter C, Bruggermann D. Use of complementary and alternative medicine in departments of obstetrics in Germany. Forschende Komplementärmedizin 2009; 16: 111-116.

22) Goodfriend C. Aromatherapy for Pregnancy and Birth. International Journal of Childbirth Education 2001; 16(3): 18-9.

23) Battaglia S. The Complete Guide to Aromatherapy. The International Centre of Holistic Aromatherapy, Brisbane Australia, 2003.

24) Long L, Huntley A, Ernst E. Which complementary and alternative therapies benefit which conditions? A survey of the opinions of 223 professional organisations. Complementary Therapies in Medicine 2001; 9: 178-185.

25) Battaglia S. (2008) The Complete Guide to Aromatherapy, 2nd edition, The International Centre of Holistic Aromatherapy, Brisbane. 
26) So M, Buzzo P, Inoue M, Einarson A. Safety of antihistamines in pregnancy and lactation. Canadian Family Physician 2010; 56(5): 427-428.

27) Shaheen SO, Newson RB, Henderson AJ, Headley JE, Stratton FD, Jones RW, Strachan DP. Prenatal paacetamol exposure and risk of asthma and elevated immunoglobulin E in childhood. Clinical \& Experimental Allergy 2005; 35: 18-25.

28) Marcus DA. Managing headaches during pregnancy and lactation. Neurotherapeutics 2008; 8(3): 385-395.

29) Lee C, Dobson AJ, Brown WJ, Bryson L, Byles J, Warner-Smith P, Young AF. Cohort profile: The Australian Longitudinal Study on Women’s Health. International Journal of Epidemiology 2005; 34:987-991.

30) Brown WJ, Dobson AJ, Bryson L, Byles JE. Women's Health Australia: on the progress of the main study cohorts. Journal of Women's Health \& Gender Based Medicine 1999; 8: 681-688.

31) Ernst E. The safety of massage therapy. Rheumatology 2003;42:1101-1106..

32) Wardle J, Steel A. (2010) Fertility, preconception care and pregnancy. In: Sarris J, Wardle J (eds), Clinical Naturopathy: An evidence-based guide to practice, Churchill Livingstone, Sydney, pp. 622-652. 
33) Schneeberger C, Geerlings SE, Middleton P, Crowther CA. Interventions for preventing recurrent urinary tract infection during pregnancy (Review). Cochrane Database Systematic Review 2012; 11:CD009279. 
Table 1 The associations between consultations with health care practitioners and self-prescribed use of aromatherapy oils, by pregnant and non-pregnant women.

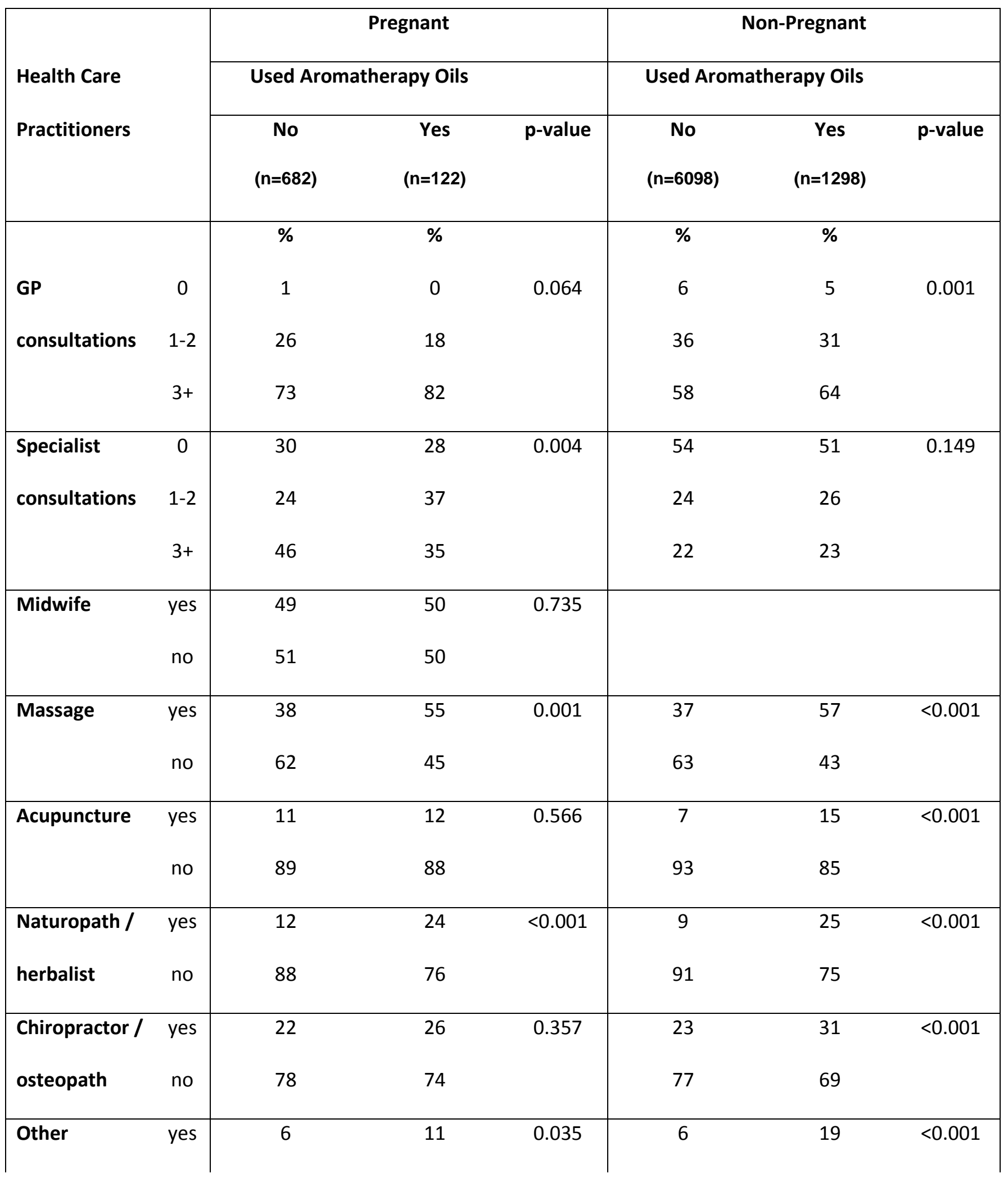


Table 2 The associations between common symptoms and diagnosed conditions and selfprescribed use of aromatherapy oils, by pregnant and non-pregnant women.

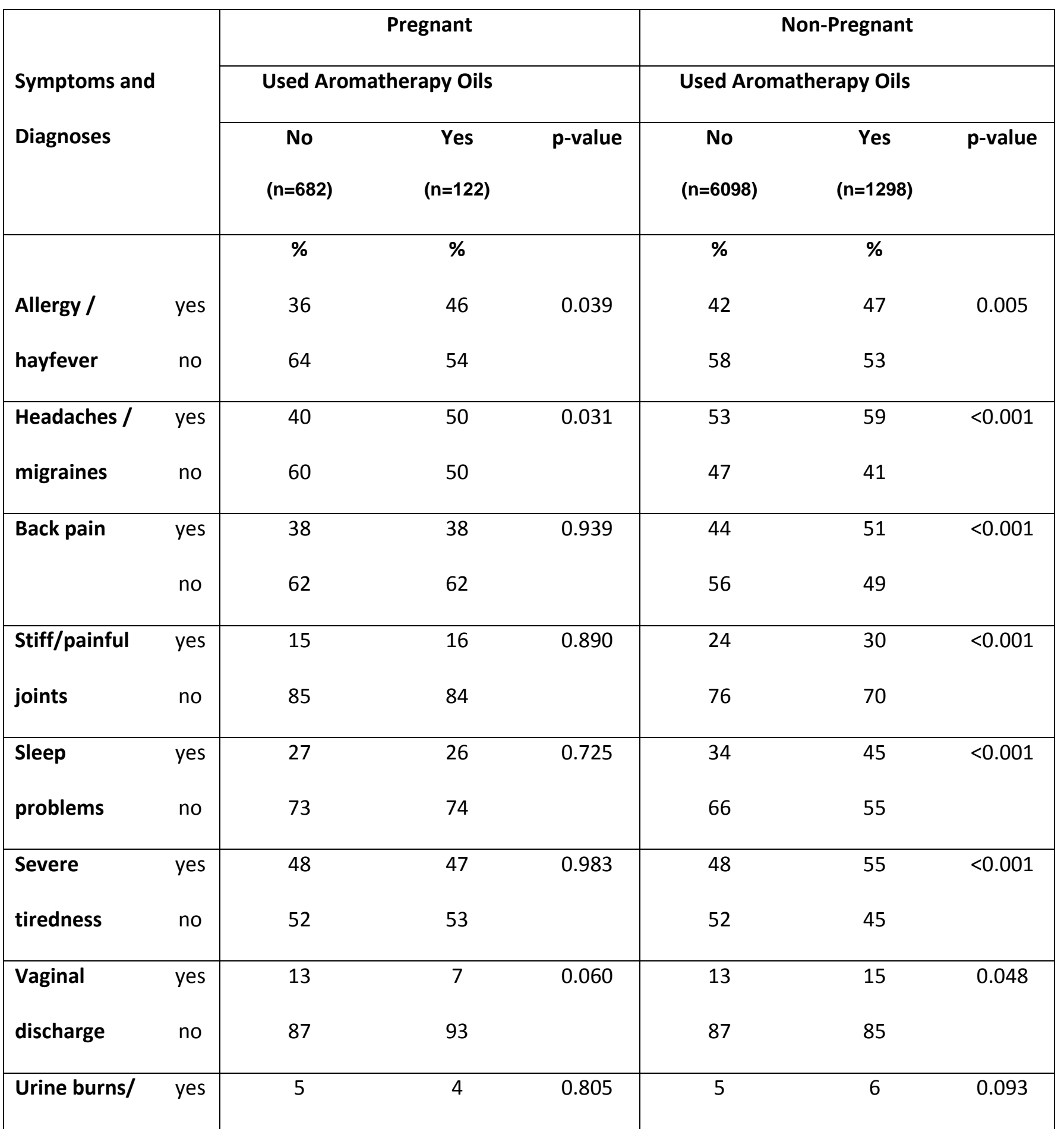




\begin{tabular}{|c|c|c|c|c|c|c|c|}
\hline stings & no & 95 & 96 & & 95 & 94 & \\
\hline Urine leaking & $\begin{array}{l}\text { yes } \\
\text { no }\end{array}$ & $\begin{array}{l}13 \\
87\end{array}$ & $\begin{array}{l}9 \\
91\end{array}$ & 0.267 & $\begin{array}{l}11 \\
89\end{array}$ & $\begin{array}{l}11 \\
89\end{array}$ & 0.909 \\
\hline UTI & $\begin{array}{l}\text { yes } \\
\text { no }\end{array}$ & $\begin{array}{l}13 \\
87\end{array}$ & $\begin{array}{l}25 \\
75\end{array}$ & 0.003 & $\begin{array}{l}14 \\
86\end{array}$ & $\begin{array}{l}18 \\
82\end{array}$ & 0.002 \\
\hline Haemorrhoids & $\begin{array}{l}\text { yes } \\
\text { no }\end{array}$ & $\begin{array}{l}12 \\
88\end{array}$ & $\begin{array}{l}10 \\
90\end{array}$ & 0.513 & $\begin{array}{l}11 \\
89\end{array}$ & $\begin{array}{l}12 \\
88\end{array}$ & 0.695 \\
\hline $\begin{array}{l}\text { Low iron } \\
\text { levels }\end{array}$ & $\begin{array}{l}\text { yes } \\
\text { no }\end{array}$ & $\begin{array}{l}17 \\
83\end{array}$ & $\begin{array}{l}19 \\
81\end{array}$ & 0.657 & $\begin{array}{l}17 \\
83\end{array}$ & $\begin{array}{l}22 \\
78\end{array}$ & $<0.001$ \\
\hline Depression & $\begin{array}{l}\text { yes } \\
\text { no }\end{array}$ & $\begin{array}{l}11 \\
89\end{array}$ & $\begin{array}{l}15 \\
85\end{array}$ & 0.218 & $\begin{array}{l}17 \\
83\end{array}$ & $\begin{array}{l}23 \\
77\end{array}$ & $<0.001$ \\
\hline Anxiety & $\begin{array}{l}\text { yes } \\
\text { no }\end{array}$ & $\begin{array}{c}5 \\
95\end{array}$ & $\begin{array}{l}8 \\
92\end{array}$ & 0.181 & $\begin{array}{l}10 \\
90\end{array}$ & $\begin{array}{l}15 \\
85\end{array}$ & $<0.001$ \\
\hline Asthma & $\begin{array}{l}\text { yes } \\
\text { no }\end{array}$ & $\begin{array}{l}10 \\
90\end{array}$ & $\begin{array}{l}12 \\
88\end{array}$ & 0.537 & $\begin{array}{l}10 \\
90\end{array}$ & $\begin{array}{l}11 \\
89\end{array}$ & 0.391 \\
\hline Hypertension & $\begin{array}{l}\text { yes } \\
\text { no }\end{array}$ & $\begin{array}{c}3 \\
97\end{array}$ & $\begin{array}{c}2 \\
98\end{array}$ & 0.467 & $\begin{array}{c}5 \\
95\end{array}$ & $\begin{array}{c}5 \\
95\end{array}$ & 0.427 \\
\hline
\end{tabular}

